\title{
A predictive model for the wettability of chalk
}

\author{
Meysam Nourani ${ }^{1}$ D . Niels Hemmingsen Schovsbo ${ }^{1} \cdot$ Ashkan Jahanbani Ghahfarokhi $^{2}$. Carsten Møller Nielsen ${ }^{1}$. \\ Lykourgos Sigalas $^{1} \cdot$ Aurelien Gabriel Meyer $^{3} \cdot$ Dan Olsen $^{1} \cdot$ Lars Stemmerik $^{1}$
}

Received: 17 May 2020 / Accepted: 26 August 2020 / Published online: 8 September 2020

(c) The Author(s) $2020 \quad$ OPEN

\begin{abstract}
Wettability is usually measured in special core analyses of limited plug samples according to typically costly and timeconsuming procedures. For comparative purposes, wettability is considered an index. The two most frequently used wettability indices are the Amott-Harvey wettability index and the U.S. Bureau of Mines (USBM) index. The Amott-Harvey wettability index is linked to imbibition characteristics and the USBM index is associated with the area under capillary pressure curves. To provide a fast analytical method, a mathematical model for predicting the wettability of chalk is presented. The model is calibrated using experimental wettability data and subsequently applied to two wells in Danish chalk oil fields in the North Sea and to outcrop chalk samples. The model supplements traditional labor-intensive laboratory measurements and predicts water wettability variations with depth by modeling both depth and porosity dependencies; in addition, it provides estimates of the effects of the aging time and displacement temperature of chalk wettability measurements in the laboratory.
\end{abstract}

Keywords Chalk $\cdot$ Wettability $\cdot$ Porosity $\cdot$ Aging time $\cdot$ Displacement temperature

\section{Introduction}

Wettability is defined as the tendency of a fluid to adhere to the surface of a solid material or spread in the presence of other immiscible fluids [1,2]; it has a critical influence on multiphase flow properties both when one fluid displaces another and when fluids are at equilibrium in a static or flowing system [1, 3]. Wettability remains an important reservoir property during the entire reservoir life cycle, from initial oil migration to field development and oil production $[2,3]$. The chalk fields in the Danish part of the North Sea are complex and challenging to develop due to the high-porosity (20-40\%) and low-permeability (0.1-10 mD) nature of the reservoirs. Production is from the Upper Cretaceous and Danian low-permeability Tor and Ekofisk formations and the Lower Cretaceous very low-permeability reservoirs of the Tuxen and Sola Formations [4-6].
In chalk fields, water flooding is commonly applied to provide pressure support. The technique has been successfully applied in the Tor Formation to increase oil recovery, and it has technical potential for improved oil recovery in the Ekofisk Formation [7-9] and theoretically the Lower Cretaceous formations. The success of improved oil recovery in chalk fields by water flooding is highly dependent on the wetting conditions of the reservoir rocks $[10,11]$.

Wettability is usually measured based on a limited sample set due to costly and time-consuming measurement procedures. For comparative purposes, wettability is generally considered an index [12]. The two most frequently used indices are the Amott-Harvey (AH) index and the U.S. Bureau of Mines (USBM) wettability index $[13,14]$. The AH index, $I_{A H}$, is related to the imbibition characteristics of the sample (AH), and the USBM index is related to the area

$\triangle$ Meysam Nourani, meytham@gmail.com | 'Reservoir Geology Department, Geological Survey of Denmark and Greenland (GEUS), Copenhagen, Denmark. ${ }^{2}$ Department of Geoscience and Petroleum, Norwegian University of Science and Technology (NTNU), Trondheim, Norway. ${ }^{3}$ Natural History Museum, University of Copenhagen, Copenhagen, Denmark. 
under the capillary pressure curve. Both approaches are very time-consuming and expensive [15].

Alternatively, wettability can be determined by measuring the static and/or dynamic contact angle between the rock and fluids. Static contact angles can be obtained by measuring and averaging the contact angles outside the oil droplet in the water drop on a surface in a surrounding fluid of water [16]. Dynamic contact angle values are either water-receding or water-advancing. The receding angle is measured by retreating the drop from the surface, whereas an advancing contact angle is measured by extending the periphery of an oil drop over a surface. The difference between receding and advancing is referred to as contact angle hysteresis [17-19].

The $\mathrm{AH}$ index is calculated by subtracting the Amott index of oil, $I_{O}$, from water, $I_{W} \cdot I_{A H}=+1$ is characterized as strongly water-wet, $I_{A H}=+0.3$ to -0.3 as neutral wet, and $I_{A H}=-1.0$ as strongly oil-wet [13]. The contact angle ranges from $0^{\circ}$ to $60^{\circ}-75^{\circ}$ for the water-wet case, from $105^{\circ}-120^{\circ}$ to $180^{\circ}$ for oil-wet rocks, and from $60^{\circ}-75^{\circ}$ to $105^{\circ}-120^{\circ}$ under neutral wettability conditions $[1,17]$.

Chalk usually contains calcite and a small proportion of silica. Minor amounts of silicate minerals are present, mainly in the form of clay [20]. Wettability is generally controlled by the mineralogical composition [21]. Exposure of two different chalk materials to the same crude oil will yield different wetting characteristics due to the different surface chemistries [22]. Therefore, considering mineralogical composition is crucial for characterizing chalk wettability. Under natural reservoir conditions, the surface charge of chalk is positive, in contrast to silica and clay, which are negative; consequently, the wetting condition is expected be controlled by the content of silica and clay [23].

The porosity of chalk is related to the primary sediment composition and subsequent diagenetic history [24]. Based on multivariate descriptor relationships, Nourani et al. [25] showed that the porosity of chalk is mainly dominated by five major elements ( $\mathrm{Ca}, \mathrm{Si}, \mathrm{Al}, \mathrm{Fe}$ and $\mathrm{K})$. $\mathrm{Ca}$, $\mathrm{Si}$ and $\mathrm{Al}$ in chalk samples originate from calcite, silica and clay, respectively.

As both the porosity and wetting behavior of chalk are related to calcite, silica and clay content, a link between porosity and wettability is expected and warrants further investigation. The objectives of this analytical-experimental study are to investigate the general relationship between the porosity and wettability of chalk samples and to develop a mathematical model for wettability by predicting contact angles under different conditions, such as for different depths, aging times and displacement temperatures. The model is calibrated using porosity and measured wettability data for samples from deep wells and chalk outcrops.

SN Applied Sciences

\section{Development of the wettability model}

Spiteri et al. [26] plotted $I_{W}$ and $I_{A H}$ indices versus the contact angle. The linear relationships between the Amott indices and static contact angle (degree) were extracted from the plots as follows:

$\theta=-44.79 I_{A H}+89.54$

$\theta=-19.10 I_{W}+79.71$

Considering its physical properties, chalk is a remarkably homogeneous sedimentary rock [24]. The liquid permeability $\left(K_{l}\left[\mathrm{~m}^{2}\right]\right)$ is related to a porosity-dependent factor $(c)$, the specific surface area per unit grain volume $\left(S_{s}\left[\mathrm{~m}^{2} \mathrm{~m}^{-3}\right]\right)$ and the porosity ( $\varphi$ [fraction]) by the Kozeny [27] equation as follows:

$K_{l}=c(\varphi) \frac{\varphi^{3}}{(1-\varphi)^{2} S_{s}^{2}}$

This equation is based on Poiseuille flow through a pipe, where the assumptions are that the fluid is incompressible and Newtonian; the flow is laminar through a pipe of constant circular cross-section that is significantly longer than its diameter; and there is no acceleration of the fluid in the pipe. Mortensen et al. [28] showed that the Kozeny equation is valid for chalk and proposed that $c$ is calculated using the following equation:

$c=\left[4 \cos \left(\frac{1}{3} \arccos \left(64 \varphi \pi^{-3}-1\right)+\frac{4}{3} \pi\right)+4\right]^{-1}$

Equation 4 is derived analytically from a simple porosity circular tubes model and Poiseuille's law. The simplified correlation between $c$ and porosity can be described by the following equation with a correlation coefficient $\left(R^{2}\right)$ of 0.99 :

$c=0.1773 e^{0.74 \varphi}$

The effective pore throat radius (also called the mean hydraulic radius) [29] can be calculated as follows:

$R_{\text {eff }}=\sqrt{\frac{K_{l}}{\varphi}}$

Capillary pressure is influenced by the pore geometry, wettability and interfacial tension and demonstrates the interaction of rock and fluids [30]. Equation 7 expresses the relationship between the pore throat radius and capillary pressure [31]: 
$P_{c w o}=\frac{2 \gamma_{w o} \cos \theta_{w o}}{R}$

where $\gamma_{w o}$ and $P_{c w o}$ are the interfacial tension between oil and water and the water-oil capillary pressure, respectively. By considering the effective pore throat radius in Eq. 7 and combining Eqs. 3, 6 and 7, the specific surface area per unit grain volume can be calculated from the following equation:

$S_{s}=\sqrt{c(\varphi)} \frac{\varphi}{(1-\varphi)} \frac{P_{c w o}}{2 \gamma_{w o} \cos \theta_{w o}}$

Formulating Eq. 8 for two samples of the same fluid, i.e., a main sample and a reference sample (referred to as subscript 0 ), yields the following expression:

$\frac{S_{s}}{S_{s_{0}}}=\frac{\sqrt{c(\varphi)}}{\sqrt{c\left(\varphi_{0}\right)}} \frac{\varphi\left(1-\varphi_{0}\right)}{\varphi_{0}(1-\varphi)} \frac{P_{c w o}}{P_{c w o}} \frac{\cos \theta_{w o_{0}}}{\cos \theta_{w o}}$

$\gamma_{w o}$ is the same for both the main and the reference samples and therefore is not included in Eq. 9. The ratio of the water-oil capillary pressures is assumed to be proportional to the air-mercury capillary pressures.

$\frac{P_{c w o}}{P_{c w o}}=k \frac{P_{c}}{P_{c_{0}}}$

where $k$ is proportionality constant. The mercury injection capillary pressure (MICP) of chalk samples was measured by SKM Services Ltd. (Aberdeen, UK). Between the entry pore throat radius and the effective pore throat radius (calculated by Eq. 6), a correlation coefficient of 0.87 was obtained, indicating proportionality between the air-mercury capillary pressure at the effective pore throat radius and the air-mercury capillary entry pressure (Fig. 1). Therefore, we replace the ratio of the water-oil capillary pressures in Eq. 9 with $k \frac{P_{c e}}{P_{c e_{0}}}$ and find the contact angle as follows:

$\theta_{w o}=\operatorname{Arccos}\left[A \frac{\sqrt{c(\varphi)} \varphi P_{c e}}{(1-\varphi) S_{s}}\right]$

where $P_{c e}$ is air-mercury capillary entry pressure. $A$ is a constant based on the properties of the reference sample and proportionality constant:

$A=\frac{\mathrm{k}\left(1-\varphi_{0}\right) S_{s_{0}} \cos \theta_{w o_{0}}}{\sqrt{c\left(\varphi_{0}\right)} \varphi_{0} P_{c e_{0}}}$

Røgen and Fabricius [20] introduced an empirical correlation relating the specific surface area per unit grain volume, porosity and capillary entry pressure of chalk (in

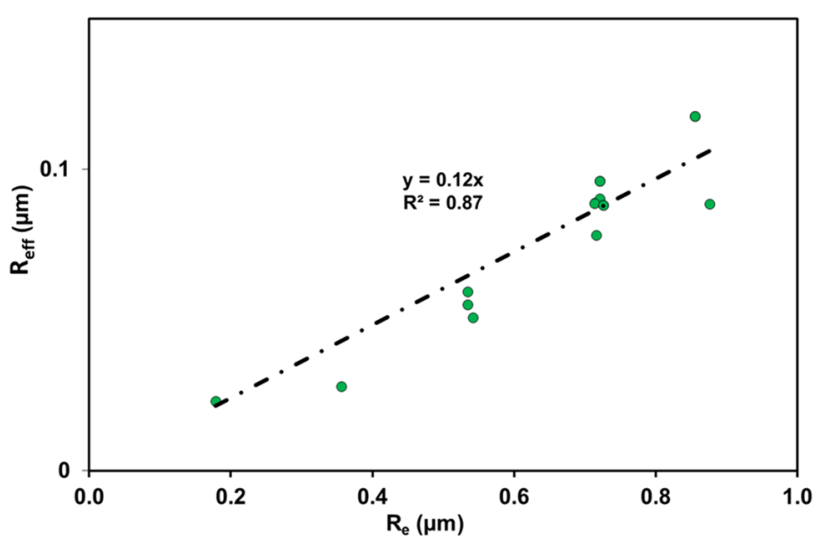

Fig. 1 Relation between the entry pore throat radius and effective pore throat radius. The dashed line shows the linear regression

psi) (valid for chalk samples with calcite contents greater than $80 \%)$ :

$P_{c e}=20+24 \frac{S_{s}(1-\varphi)}{\varphi}$

By combining Eqs. 3, 5, 11 and 13, the contact angle can be calculated using the following formula:

$\theta_{w o}=\operatorname{Arccos}\left(20 A K_{l}^{0.5} \varphi^{-0.5}+10.11 A e^{0.37 \varphi}\right)$

The term $\left(20 A K_{l}^{0.5} \varphi^{-0.5}\right)$ is negligible compared to $\left(10.11 A e^{0.37 \varphi}\right)$.

Jakobsen et al. [5] developed linear relationships between the insoluble residual (IR) content and porosity for chalk formations in the Valdemar Field. The IR is primarily related to clay and silica. Extrapolating the linear relationships led to zero porosity at $79 \%$ and $96 \%$ IR for the Tuxen and Sola Formations, respectively. Strand et al. [22] reported a more water-wet condition in the presence of IR content due to the negative charge of silica and clay to stabilize the water film, coating the chalk surface and prohibiting the overlaying oil from reaching the surface. The fine pores and grain contacts are preferentially water-wet [32], and it is implicitly assumed that fine clay-rich rocks are characteristically water-wet [33].

If the IR content reaches high values, we expect nearzero porosity and, consequently, a completely wetted situation and a contact angle equal to zero. Therefore, the coefficient (10.11A) in Eq. 14 must be one to obtain a zero contact angle at zero porosity. Therefore:

$\theta_{\text {wo }}=\operatorname{Arccos}\left(e^{0.37 \varphi}\right)$

Hence, the model is no longer dependent on the reference sample properties. The wettability of chalk can be predicted from Eq. 15 if the porosity is known, but it 
should be noted that wettability is a state that is energywise favorable when chalk is in contact with a specific type of oil or water. The fluids, namely, oil and water, rearrange to decrease the energy state [3]. This relation is mathematically represented as follows [34]:

$\cos \theta_{w o}=\frac{\gamma_{s o}^{2}-\gamma_{s w}^{2}+\gamma_{w o}^{2}}{2 \gamma_{s o} \gamma_{w o}}$

Equation 16 is based on the theory of minimizing the energy in the solid/oil/water system, where $\gamma_{s o}$ and $\gamma_{s w}$ are the oil-solid surface tension and water-solid surface tension, respectively. Because Eq. 15 is developed based on a reference oil and water system, it must be calibrated with a set of wettability measurements for specified fluids at specified measurement conditions. Therefore, an empirical correction factor, $\alpha$, is considered to specify the reference fluids and include the effects of different conditions, such as the aging time, temperature and depth, on wettability. This factor is introduced in Eq. 15 as follows:

$\theta_{\text {wo }}=\operatorname{Arccos}\left(e^{0.37 \alpha \varphi}\right)$

Equation 17 is valid for $\alpha<0$. For a positive $\alpha$, the contact angle is zero. The empirical correction factor, $\alpha$, is not unique and is used to overcome the deficiencies in considering various factors affecting wettability. $\alpha$ is a dimensionless number that must be adjusted to improve the accuracy of the predictive wettability model.

Figure 2 shows a sketch of the problem presented in this study. The outlined method can be combined with experimental wettability data obtained with calibration and porosity logging tools, such as neutron porosity and sonic devices, to evaluate the in situ wettability of chalk. In addition, the model can be used to define a new-format capillary number specific to chalk. This is a dimensionless number that describes the ratio of viscous to capillary forces acting across the interface of two immiscible fluids. Moore and Slobod [35] defined the capillary number as follows:

Fig. 2 A schematic general

sketch of the problem
$N_{c}=\frac{\mu v}{\gamma_{w o} \cos \theta_{w o}}$

where $\mu$ is the viscosity of the displacement phase and $v$ is the velocity of the displacement phase. By combining Eqs. 17 and 18, the specified capillary number can be obtained as follows:

$N_{c}=\frac{\mu v}{\gamma_{w o} e^{0.37 \alpha \varphi}}$

The maximum oil recovery via the water flooding of chalk occurs under wettability conditions close to neutral-wet conditions [10]. According to Eq. 17 and the new expression of the capillary number (Eq. 19), increasing the porosity leads to a decrease in the capillary pressure and an increase in the capillary number. Therefore, increasing the porosity leads to increased oil recovery by water flooding.

\section{Validating the model}

Two Amott wettability index datasets were used to define $\alpha$ and apply the developed method.

\subsection{North Sea chalk reservoir samples}

The first dataset includes 13 North Sea chalk reservoir samples from four major formations; Tor, Maastrichtian, Ekofisk and Hod, as listed in Table 1. The data were reported as part of the Joint Chalk Research Program by Christensen et al. [36]. Figure 3 exhibits a schematic diagram to illustrate the applied procedure for determining the Amott wettability index values. The samples were fresh and cleaned by flushing the plugs at $60^{\circ} \mathrm{C}$ with $20-30$ pore volumes of light synthetic oil (Isopar L). The plugs were then submerged in formation water, and spontaneous water imbibition was performed. As an equilibrium condition, no oil production by spontaneous imbibition within three days was

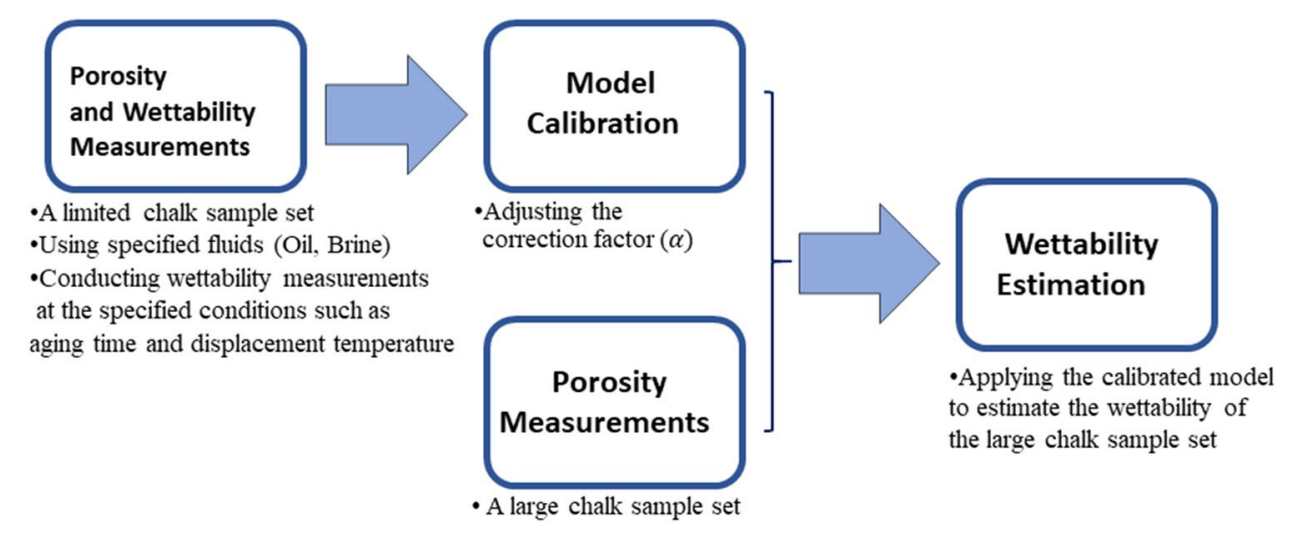


Table 1 Measured and calculated wettability indices of chalk samples from selected North Sea fields [38]

\begin{tabular}{|c|c|c|c|c|c|c|c|c|}
\hline No. & Formation & TVDSS (m) & $\varphi(\%)$ & $\mathrm{I}_{\mathrm{AH}}$ & $\begin{array}{l}\text { Calculated } \\
\text { a, Eq. } 20\end{array}$ & $\begin{array}{l}\text { Calculated } \\
\theta\left({ }^{\circ}\right) \text {, Eq. } 1\end{array}$ & $\begin{array}{l}\text { Calculated } \theta\left({ }^{\circ}\right), \\
\text { Eqs. } 17 \text { and } 20\end{array}$ & $\operatorname{Er}(\%)$ \\
\hline 1 & Tor & 3286.05 & 43.91 & -0.025 & -37.44 & 90.7 & 89.9 & 0.9 \\
\hline 2 & Tor & 3286.13 & 42.67 & -0.008 & -37.44 & 89.9 & 89.8 & 0.1 \\
\hline 3 & Tor & 3286.30 & 44.04 & -0.031 & -37.45 & 90,9 & 89.9 & 1.2 \\
\hline 4 & Maastrichtian & 2064.64 & 36.44 & 0.659 & -5.81 & 60.0 & 62.8 & -4.6 \\
\hline 5 & Maastrichtian & 2064.64 & 36.76 & 0.654 & -5.81 & 60.2 & 63,0 & -4.6 \\
\hline 6 & Maastrichtian & 2064.64 & 36.65 & 0.587 & --5.81 & 63.2 & 62.9 & 0.5 \\
\hline 7 & Ekofisk & 3127.93 & 41.6 & 0.030 & -33.35 & 88.2 & 89.7 & -1.7 \\
\hline 8 & Ekofisk & 3128.04 & 41.71 & 0.020 & -33.35 & 88.6 & 89.7 & -1.2 \\
\hline 9 & Ekofisk & 3144.07 & 35.41 & 0.020 & -33.77 & 88.6 & 89.3 & -0.8 \\
\hline 10 & Ekofisk & 3143.93 & 31.7 & 0.040 & -33.76 & 87.7 & 88.9 & -1.3 \\
\hline 11 & Hod & 2592.83 & 30.67 & 0.04 & -19.49 & 87.7 & 83.7 & 4.6 \\
\hline 12 & Hod & 2593.67 & 28.73 & 0.09 & -19.51 & 85.5 & 82.8 & 3.2 \\
\hline 13 & Hod & 2594.40 & 25.6 & 0.03 & -19.53 & 88.2 & 81.0 & 8.2 \\
\hline
\end{tabular}

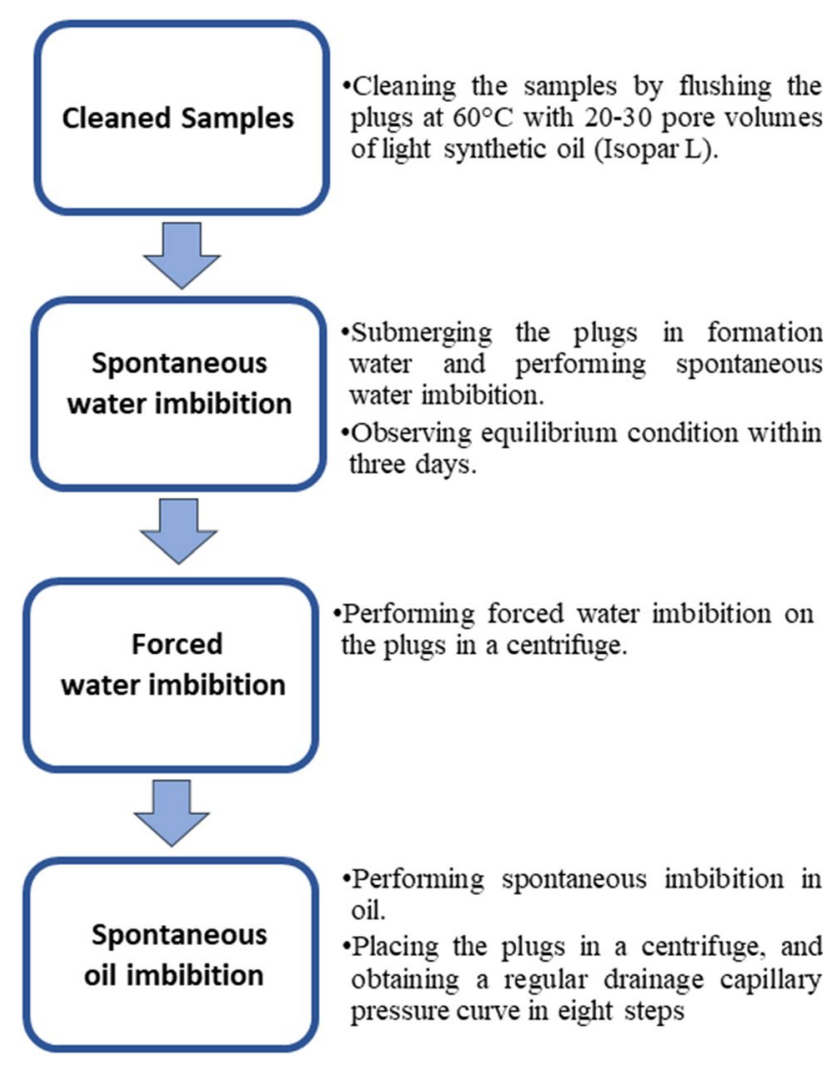

Fig. 3 Schematic diagram of the applied procedure to measure the Amott wettability index values [36]

observed. Forced water imbibition was then performed on the plugs in a centrifuge. Next, spontaneous imbibition in oil was performed. The plugs were again placed in a centrifuge, and a regular drainage capillary pressure curve was obtained in eight steps [36]. The measured $\mathrm{I}_{\mathrm{AH}}$ values were converted to contact angles by Eq. 1 .
The $a$ values (Table 1) were selected in such a way to result in linear behavior between $a$ and depth, and the estimated contact angles from Eq. 17 matched the experimental data (the relative error is less than 10\%). Very good agreement $\left(R^{2}=0.95\right)$ between the modelestimated contact angle and measured Amott wettability index was observed, as listed in Table 1. The developed model correctly predicted water-wet conditions for samples 4, 5 and 6 and neutral wetting for the rest of the samples.

Equation 20 expresses the relationship between depth and $a$ as follows:

$\alpha=-0.0259 \mathrm{D}+47.666$

where $D$ is the TVDSS in meters.

Taking the derivative of Eqs. 17 and 20 with respect to depth yields the following equations:

$\frac{\partial \theta_{w o}}{\partial D}=-0.37 \cot \theta\left(\varphi \frac{\partial \alpha}{\partial D}+\alpha \frac{\partial \varphi}{\partial D}\right)$

$\frac{\partial \alpha}{\partial D}=-0.0259$

When the water wetness increases with depth, the derivative of the contact angle with respect to depth must be negative. Therefore, for $0<\theta<90$ :

$\left(\varphi \frac{\partial \alpha}{\partial D}+\alpha \frac{\partial \varphi}{\partial D}\right)>0$

By combining Eqs. 20 and 22 with inequality 23, the condition that leads to increased water wetness with depth can be expressed as follows: 
$\frac{\partial \varphi}{\partial D}<\frac{0.0259 \varphi}{(47.666-0.0259 D)}$

Using Eqs. 17 and 20, the contact angles were calculated for different depths and porosities, as shown in Fig. 4. Four main trends were detected. The first trend indicates

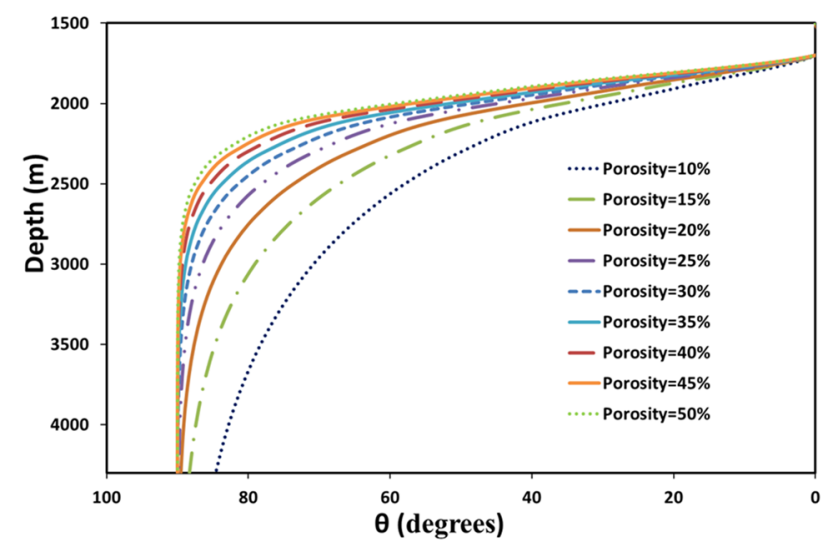

Fig. 4 Relation between the calculated contact angles (using Eqs. 17 and 20) and different TVDSSs that at constant porosity, water wetness decreases and the contact angle increases with depth. The second trend shows that at constant depth, water wetness decreases and the contact angle increases with porosity. These trends confirm and support each other.

The third trend indicates that water wetness decreases and the contact angle increases with depth and porosity. The fourth trend reveals that the water wetness increases and the contact angle decreases with increasing depth and decreasing porosity. The general trend in the chalk fields is a decline in porosity with depth [3]. Therefore, the fourth trend seems the most applicable to chalk reservoirs, but the third trend may also be applicable in some cases.

\subsection{Rørdal outcrop chalk samples}

The second Amott wettability index dataset includes 25 chalk samples from Rørdal Quarry in NW Denmark (Table 2). Figure 5 shows the schematic diagram to explain the applied procedure to determine the Amott water wettability index values. All the samples were aged at $90^{\circ} \mathrm{C}$ and flooded with oil at two different temperatures of $45^{\circ} \mathrm{C}$ and $90^{\circ} \mathrm{C}$. (This dataset overcomes any possible limitations related to the
Table 2 Measured wettability indices of outcrop chalk samples from the Rørdal quarry [10]

\begin{tabular}{|c|c|c|c|c|c|c|c|c|}
\hline No. & Aging time $(\mathrm{d})$ & $\varphi(\%)$ & $\operatorname{Temp}\left({ }^{\circ} \mathrm{C}\right)$ & $I_{w}$ & $\begin{array}{l}\text { Calculated } \\
a, \text { Eq. } 25\end{array}$ & $\begin{array}{l}\text { Calculated } \\
\theta\left({ }^{\circ}\right), \text { Eq. } 2\end{array}$ & $\begin{array}{l}\text { Calculated } \theta\left({ }^{\circ}\right), \\
\text { Eqs. } 17 \text { and } 25\end{array}$ & $\operatorname{Er}(\%)$ \\
\hline 1 & 4 & 46.5 & 45 & 0.89 & -4.48 & 62.71 & 62.46 & 0.4 \\
\hline 2 & 4 & 46.8 & 45 & 0.84 & -4.48 & 63.67 & 62.61 & 1.7 \\
\hline 3 & 9 & 46.4 & 45 & 0.86 & -5.21 & 63.28 & 65.88 & -4.1 \\
\hline 4 & 9 & 46.7 & 45 & 0.81 & -5.21 & 64.24 & 66.03 & -2.8 \\
\hline 5 & 9 & 46.8 & 45 & 0.75 & -5.21 & 65.39 & 66.08 & -1.1 \\
\hline 6 & 14 & 46.4 & 45 & 0.63 & -5.94 & 67.68 & 68.87 & -1.8 \\
\hline 7 & 14 & 47.3 & 45 & 0.75 & -5.94 & 65.39 & 69.30 & -6.0 \\
\hline 8 & 14 & 47.0 & 45 & 0.77 & -5.94 & 65.00 & 69.16 & -6.4 \\
\hline 9 & 14 & 46.9 & 45 & 0.75 & -5.94 & 65.39 & 69.11 & -5.7 \\
\hline 10 & 28 & 47.1 & 45 & 0.07 & -7.99 & 78.37 & 75.61 & 3.5 \\
\hline 11 & 28 & 46.8 & 45 & 0.04 & -7.99 & 78.95 & 75.47 & 4.4 \\
\hline 12 & 28 & 47.1 & 45 & 0.09 & -7.99 & 77.99 & 75.61 & 3.1 \\
\hline 13 & 1 & 46.7 & 90 & 0.82 & -5.13 & 64.05 & 65.64 & -2.5 \\
\hline 14 & 1 & 46.7 & 90 & 0.81 & -5.13 & 64.24 & 65.64 & -2.2 \\
\hline 15 & 3 & 46.8 & 90 & 0.61 & -5.42 & 68.06 & 66.96 & 1.6 \\
\hline 16 & 3 & 47 & 90 & 0.59 & -5.42 & 68.44 & 67.06 & 2.0 \\
\hline 17 & 8 & 47 & 90 & 0.34 & -6.15 & 73.22 & 69.92 & 4.5 \\
\hline 18 & 8 & 46.8 & 90 & 0.36 & -6.15 & 72.83 & 69.82 & 4.1 \\
\hline 19 & 14 & 46.6 & 90 & 0.26 & -7.02 & 74.74 & 72.67 & 2.8 \\
\hline 20 & 14 & 46.6 & 90 & 0.32 & -7.02 & 73.60 & 72.67 & 1.3 \\
\hline 21 & 14 & 46.7 & 90 & 0.37 & -7.02 & 72.64 & 72.71 & -0.1 \\
\hline 22 & 14 & 47.1 & 90 & 0.33 & -7.02 & 73.41 & 72.90 & 0.7 \\
\hline 23 & 24 & 47.5 & 90 & 0.23 & -8.48 & 75.32 & 76.99 & -2.2 \\
\hline 24 & 24 & 47.6 & 90 & 0.27 & -8.48 & 74.55 & 77.03 & -3.3 \\
\hline 25 & 31 & 47.8 & 90 & 0.23 & -9.51 & 75.32 & 79.27 & -5.2 \\
\hline
\end{tabular}




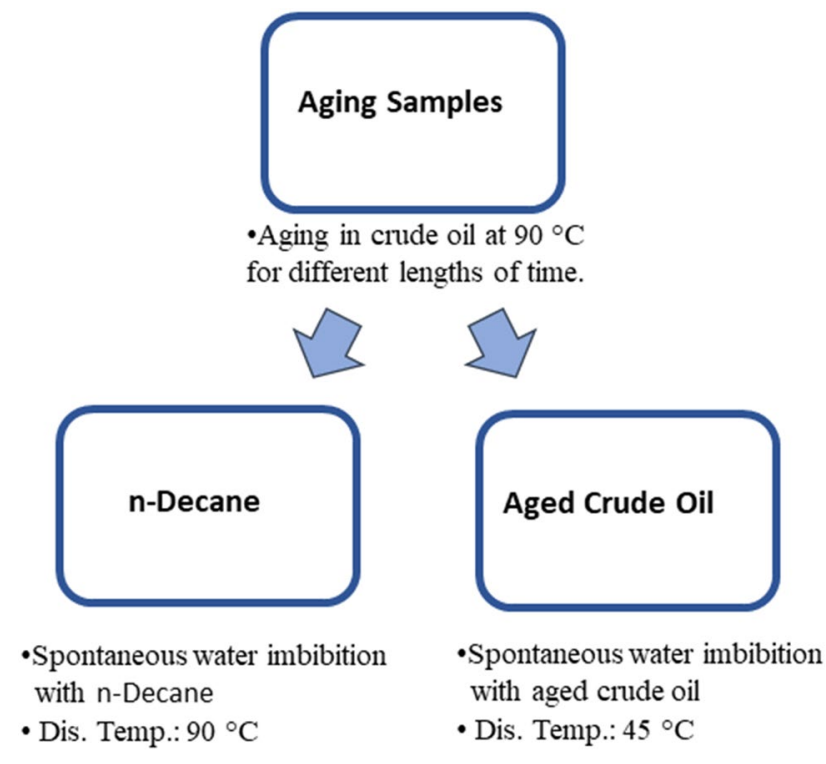

Fig. 5 Schematic diagram of the applied procedure to determine the Amott water wettability index values [10]

use of synthetic oil and the lack of aging, as in dataset 1). The aging time varied from one to 31 days (Table 2), as reported by Graue et al. [10]. The measured $I_{w}$ values were converted to contact angles by Eq. 2 .

The $a$ values were calculated from Eq. 17 using the experimental data. Equation 25 expresses the relationship between the displacement temperature $\left(T_{d}\right)$, aging time $(d)$ and $a$ with a correlation coefficient $\left(\mathrm{R}^{2}\right)$ of 0.74 :

$\alpha=-2.819-0.024 T_{d}-0.146 d$

where $d$ and $T_{d}$ are expressed in days and ${ }^{\circ} \mathrm{C}$, respectively. Fitting analysis was performed using MS Excel.

The $a$ values calculated from Eq. 25 for each aging time and displacement temperature are presented in Table 2. $a$ decreases with the aging time and displacement temperature. Considering Eq. 17, a low $a$ at constant porosity leads to weak water wetness. Therefore, increasing the aging time and displacement temperature decreases water wetness. Good agreement $\left(R^{2}=0.80\right)$ between the model-estimated contact angle and measured Amott wettability index was observed, as listed in Table 2.

Taking the derivatives of Eqs. 17 and 25 with respect to the displacement temperature yields the following equations:

$$
\begin{aligned}
& \frac{\partial \theta_{w o}}{\partial T_{d}}=-0.37 \cot \theta\left(\varphi \frac{\partial \alpha}{\partial T_{d}}+\alpha \frac{\partial \varphi}{\partial T_{d}}\right) \\
& \frac{\partial \alpha}{\partial T_{d}}=-0.024
\end{aligned}
$$

Similarly, taking the derivatives of Eqs. 17 and 25 with respect to the aging time yields the following equations:

$\frac{\partial \theta_{w o}}{\partial d}=-0.37 \cot \theta\left(\varphi \frac{\partial \alpha}{\partial d}+\alpha \frac{\partial \varphi}{\partial d}\right)$

$\frac{\partial \alpha}{\partial d}=-0.146$

Porosity does not change with variations in displacement temperature and aging time. Therefore, the derivatives of porosity with respect to displacement temperature and aging time in Eqs. 26 and 28 are equal to zero. Combining Eqs. 26 and 28 yields the following equation:

$\frac{\partial T_{d}}{\partial d}=6.1$

Equation 30 shows that contact angle alteration due to a $6.1^{\circ} \mathrm{C}$ change in the displacement temperature is equivalent to its alteration due to a change of one day in the aging time.

\section{Results and discussion}

The chalk porosity dataset used to calculate the contact angles is derived from the M-10X and E-5X wells in the North Sea and the onshore Rørdal chalk quarry in Denmark. The M-10X well is in the Dan Field, and the E-5X well is in the Tyra SE Field in the Danish part of the North Sea. Figure 6 shows the porosity distributions. The average porosities of the Rørdal quarry, well E-5X and well M-10X samples are $44.3 \%, 33.2 \%$ and $28.3 \%$, respectively. All samples are relatively pure chalk $\left(\mathrm{CaCO}_{3}\right.$ content $\left.>80 \%\right)$, with the North Sea chalk being the purest (generally $\mathrm{CaCO}_{3}$ content $>90 \%$ ). The non-chalk components include clay and silica [20]. The North Sea wells are currently at maximum burial depth, but due to high pore pressures, the effective depth is less than that reflected by the TVDSS [37]. The Rørdal samples were never buried deeper than $1 \mathrm{~km}$ and are now exposed at the surface level following the Neogene uplift [38].

Figure 7 shows the predicted contact angles for the $\mathrm{M}-10 \mathrm{X}$ and $\mathrm{E}-5 \mathrm{X}$ wells versus depth using Eqs. 17 and 20 . The predicted contact angles decrease with increasing depth and decreasing porosity in some cases (fourth trend). Nevertheless, increased contact angles with depth and porosity (third trend) can also be observed in Fig. 7 . The average predicted contact angles of wells $\mathrm{E}-5 \mathrm{X}$ and $\mathrm{M}-10 \mathrm{X}$ are approximately 54 and 30 degrees, respectively. Well E-5X has a higher average porosity and is deeper than well M-10X and displays less water wetness. 
Fig. 6 Distributions of porosity from the Rørdal quarry and the North Sea E-5X and M-10X wells: (a) Histogram and (b) Cumulative distribution (a)

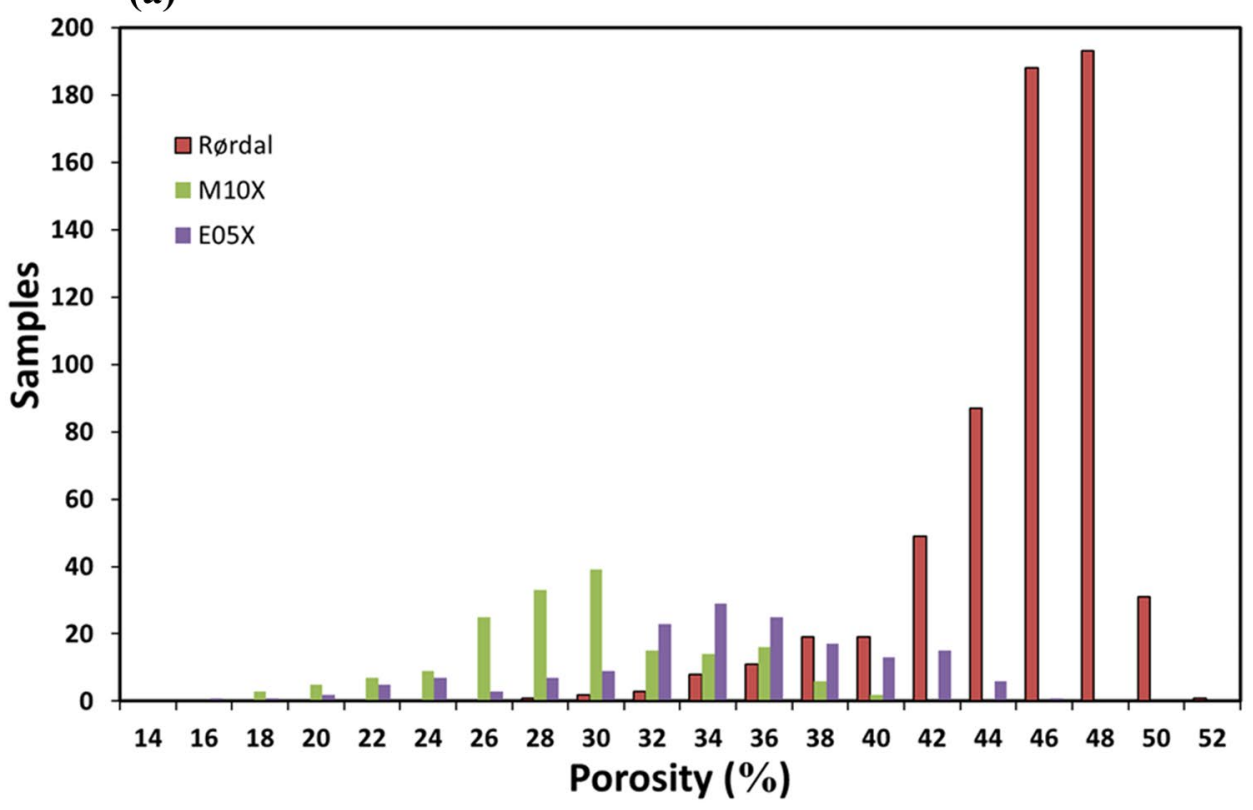

(b)

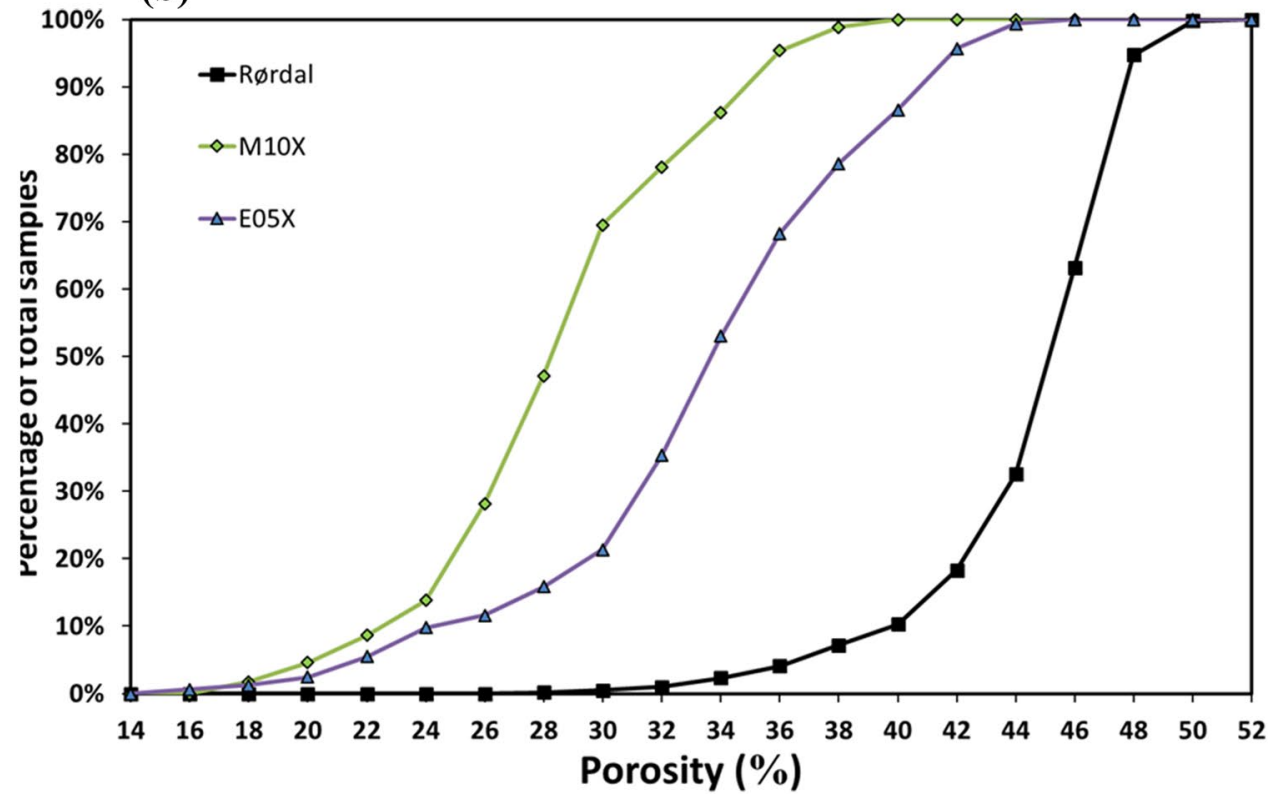

Some studies have reported that water wetness increases only slightly with depth [3], whereas others have shown a much stronger trend of increasing water wetness with depth [39-41]. According to Eqs. 17 and 20, depth and porosity have similar effects on wettability, and water wetness decreases. Porosity generally decreases with depth, and thus, we expect increased water wetness with depth. However, if porosity increases even slightly with depth, we expect that the water wetness will decrease. In the Danish North Sea, the chalk porosity does not decrease with depth due to the overpressured nature of the basin; thus, the usual depth trends are not expected [6]. The poor chalk reservoir properties are linked to the existence of clay layers and their adjacent pore-filling calcite, and the presence of large amounts of nano-quartz in the chalk. The effect on porosity is attributed to the contents of both clay minerals and nano-quartz [42]. Therefore, the water wetness tends to be higher for lower porosity due to the clay and quartz contents of chalk, which means that the surface is effectively less oil wetting [22].

Inequality 24 is valid for depths deeper than $1840 \mathrm{~m}$. The derivative of porosity with respect to depth was calculated for wells M-10X and E- 5 X. Notably, $24 \%$ and $46 \%$ of $\frac{\partial \varphi}{\partial D}$ values satisfied inequality (24) for wells $M-10 X$ and $E-5 X$, 


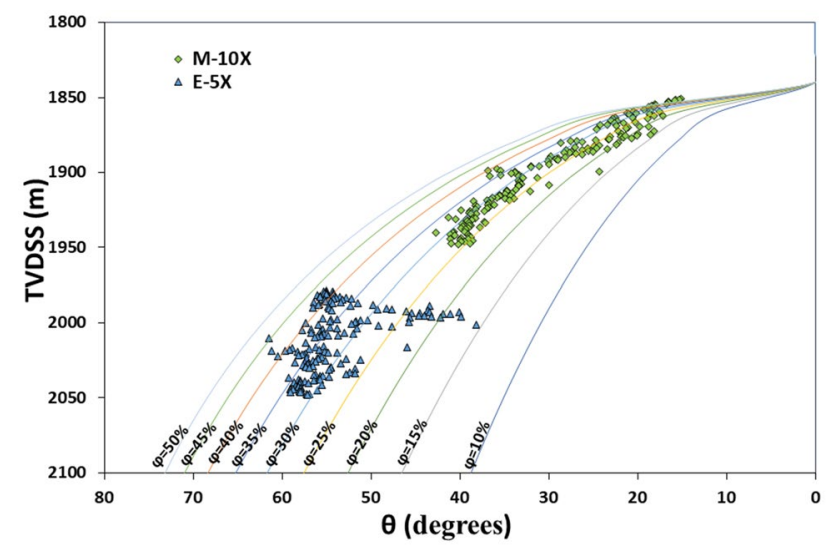

Fig. 7 Relation between the calculated contact angle (using Eqs. 17 and 20) and TVDSS at different porosities

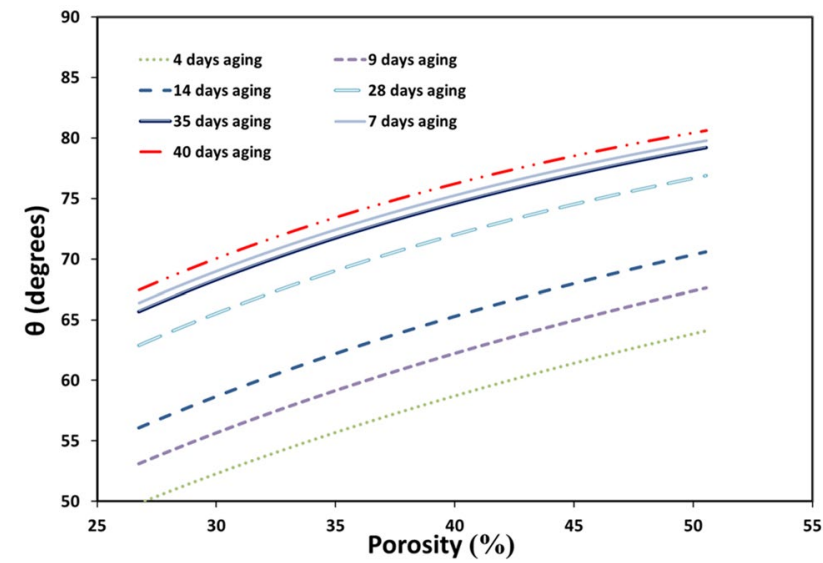

Fig. 8 Relation between the porosity and calculated contact angle at a displacement temperature of $45^{\circ} \mathrm{C}$ for Rørdal samples

respectively. Thus, water wetness decreases with depth for $76 \%$ and $54 \%$ of the samples from wells $M-10 X$ and $E-5 X$, respectively.

Figures 8 and 9 show the predicted contact angles of outcrop chalk samples from Rørdal versus the aging time at displacement temperatures of $45^{\circ} \mathrm{C}$ and $90^{\circ} \mathrm{C}$, respectively. The predicted contact angles increase with porosity and aging time. The contact angles become almost independent of the displacement temperature and reach values between $76^{\circ}$ and $78^{\circ}$ for $40 \%$ porosity when the aging time approaches 40 days. The essential aging time to re-establish reservoir wettability varies, depending on the brine, crude and reservoir rock. Generally, 40 days aging $(1,000 \mathrm{~h})$ at the reservoir temperature is well accepted to reach wetting equilibrium [43].

Figure 10 shows the cumulative distribution of the predicted contact angles of the Rørdal samples at aging times of 10, 20 and 40 days and displacement temperatures of

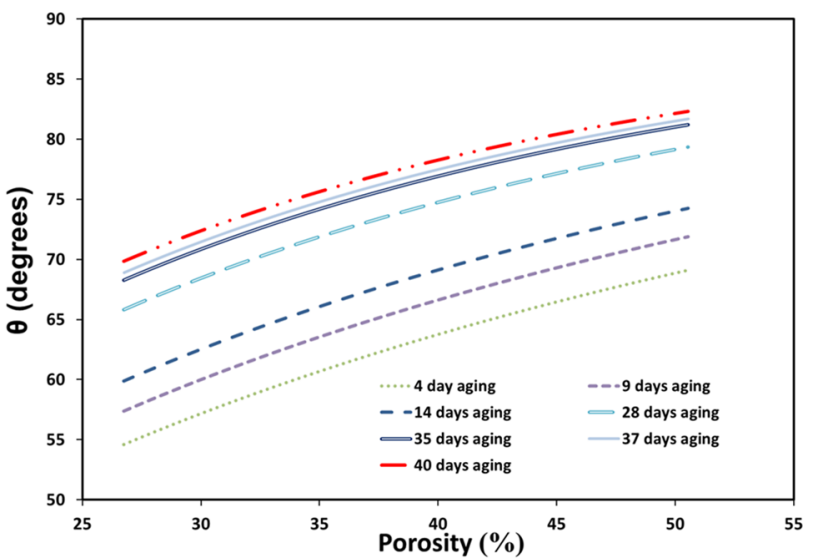

Fig. 9 Relation between the porosity and calculated contact angle at a displacement temperature of $90^{\circ} \mathrm{C}$ for the Rørdal samples

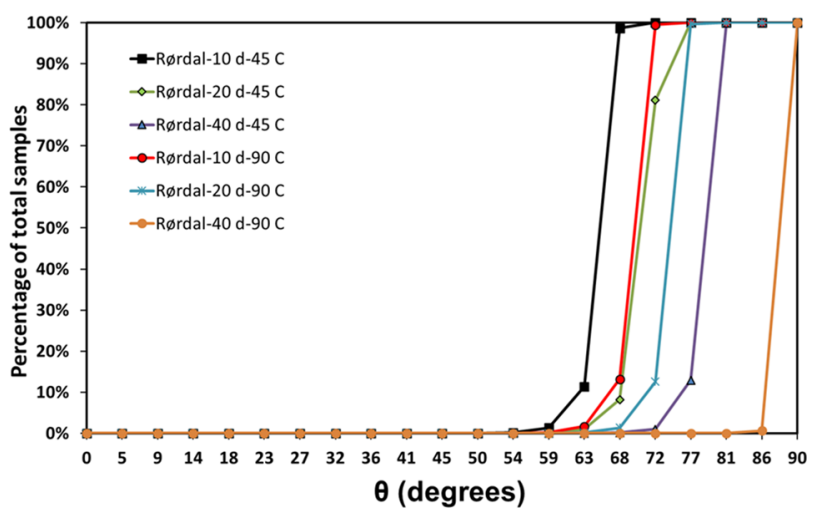

Fig. 10 Cumulative distribution of the calculated contact angle at aging times of 10,20 and 40 days and displacement temperatures of $45^{\circ} \mathrm{C}$ and $90^{\circ} \mathrm{C}$ for the Rørdal samples

$45^{\circ} \mathrm{C}$ and $90^{\circ} \mathrm{C}$ using Eqs. 17 and 25 . The Rørdal samples exhibit relatively neutral wetting conditions, in line with the results of previous studies [21,22]. Samples at an aging time of 10 days and a displacement temperature of $45^{\circ} \mathrm{C}$ exhibit more water wetness. An aging time of 20 days and a temperature of $45^{\circ} \mathrm{C}$ and an aging time of 10 days and a temperature of $90^{\circ} \mathrm{C}$ show similar effects and neutral wetting. According to Eq. 30, the effect of a $45^{\circ} \mathrm{C}$ increase in the displacement temperature on the contact angle alteration is equivalent to the effect of a 7.4 day increase in the aging time.

The calculated contact angles are plotted versus the aging times in Fig. 11 at three different porosities and two displacement temperatures for the Rørdal samples. Figure 11 shows that water wetness decreases with aging time. By increasing the displacement temperature to $80^{\circ} \mathrm{C}$ at constant porosity, the water wetness decreases for all three porosities. In contrast to the mentioned trend, a general 


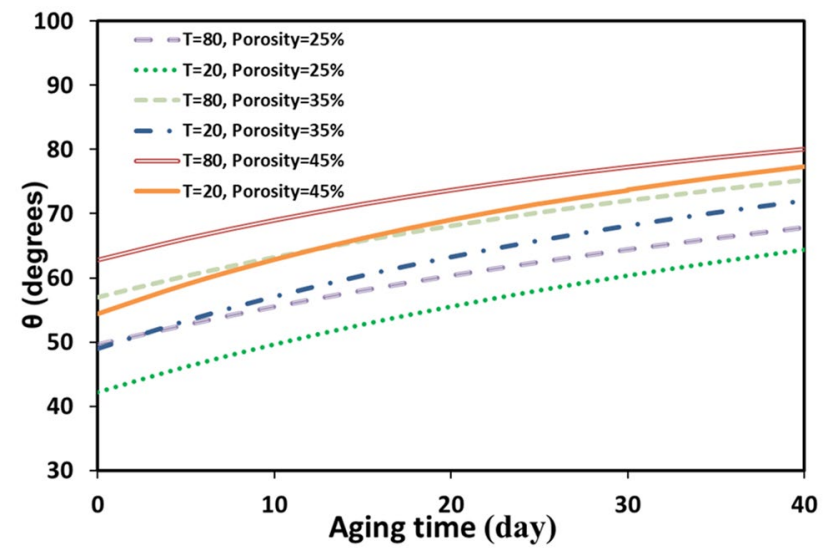

Fig. 11 Relationship between the aging time and calculated contact angle at porosities of $25 \%, 35 \%$ and $45 \%$ and displacement temperatures of $20^{\circ} \mathrm{C}$ and $80^{\circ} \mathrm{C}$ for the Rørdal samples

observation for carbonate reservoirs is that the water wetness increases as the reservoir temperature increases due to reduction in the crude oil acid number at elevated temperatures $[43,44]$. Fluid-rock interactions rely on the components of all the involved phases. As the water imbibition tests for Rørdal outcrop chalk samples were performed with two different fluids, crude oil and n-decane, at two different displacement temperatures, $45^{\circ} \mathrm{C}$ and $90^{\circ} \mathrm{C}$, the observed wettability trend with temperature is not comparable with the reported general effect of temperature on wettability of carbonate samples.

Water wetness decreases with aging time and displacement temperature because of enhanced adsorption of polar acidic and basic components of organic material that exist originally in the crude oil. The degree of water wetness reduction is determined by the interaction of the oil constituents, the mineral surface, and the brine chemistry [23, 45]. By increasing the porosity at a constant displacement temperature, the water wetness decreases due to the low amount of negatively charged silica, which is not enough to stabilize the water film to inhibit oil covering the chalk surface.

There are several assumptions in the derivation of the proposed model. Specifically, the Amott index is converted to the contact angle, the ratio of the water-oil capillary pressures is considered proportional to the air-mercury capillary pressures, and an empirical correction factor, $\alpha$, is introduced, which might impose some limitations in terms of the applicability of the model.

SN Applied Sciences

\section{Conclusions}

Based on the developed wettability model and the application of the model to three large datasets, the following conclusions can be drawn.

1. An analytical-experimental wettability model is developed that includes porosity and $\alpha$ parameters for predicting the wettability of chalk samples with calcite contents greater than $80 \%$.

2. The contact angle increases with porosity and $|\alpha|$. Additionally, $a$ is dependent on the depth, aging time and displacement temperature. Increases in depth, aging time and displacement temperature lead to an increase in $|\alpha|$.

3. An analytical-experimental inequality is proposed to predict the water wetness trend with depth.

4. A new expression of the capillary number is introduced to explain the effects of porosity on oil recovery in chalk reservoirs.

5. The developed method can be combined with experimental wettability data and porosity logging tools to evaluate the wettability of the reservoir (despite limited applicability in some cases).

Acknowledgements The authors are grateful for the financial support by the Centre for Oil and Gas-DTU/Danish Hydrocarbon Research and Technology Centre (DHRTC). We are also thankful to the Department of Reservoir Geology at the Geological Survey of Denmark and Greenland (GEUS) and the Department of Geoscience and Petroleum at Norwegian University of Science and Technology (NTNU). Mads Engberg Willumsen and Niels Springer are acknowledged for their constructive comments, recommendations and support.

Author contributions Meysam Nourani derived the mathematical model and wrote, reviewed, edited and coordinated the manuscript. Niels Hemmingsen Schovsbo had a lead contribution in data curation, derivation of the mathematical model and review \& editing. Ashkan Jahanbani Ghahfarokhi had a lead contribution in derivation of the mathematical model and review \& editing. Carsten Møller Nielsen had a lead contribution in data curation and a supporting contribution in providing resources and supervision, deriving the mathematical model and review \& editing. Lykourgos Sigalas had a supporting contribution in providing resources, deriving the mathematical model and review \& editing. Aurelien Gabriel Meyer had a supporting contribution in deriving the mathematical model and review \& editing. Dan Olsen had a lead contribution in supervision and providing resources and a supporting contribution in review \& editing. Lars Stemmerik had a lead contribution in supervision and review \& editing and a supporting contribution in providing resources.

Funding Open Access funding provided by NTNU Norwegian University of Science and Technology (incl St. Olavs Hospital - Trondheim University Hospital). This study was funded by the Centre for Oil and Gas-DTU/Danish Hydrocarbon Research and Technology Centre (DHRTC). 
Availability of data and material Not applicable.

\section{Compliance with ethical standards}

Conflict of interest The authors declare that they have no conflict of interest.

Code availability Not applicable.

Open Access This article is licensed under a Creative Commons Attribution 4.0 International License, which permits use, sharing, adaptation, distribution and reproduction in any medium or format, as long as you give appropriate credit to the original author(s) and the source, provide a link to the Creative Commons licence, and indicate if changes were made. The images or other third party material in this article are included in the article's Creative Commons licence, unless indicated otherwise in a credit line to the material. If material is not included in the article's Creative Commons licence and your intended use is not permitted by statutory regulation or exceeds the permitted use, you will need to obtain permission directly from the copyright holder. To view a copy of this licence, visit http://creativecommons .org/licenses/by/4.0/.

\section{References}

1. Anderson W (1986) Wettability literature survey- part 2: wettability measurement. J Pet Technol 38:1246-1262. https://doi. org/10.2118/13933-PA

2. Morrow NR (1990) Wettability and its effect on oil recovery. J Pet Technol 42:1476-1484. https://doi.org/10.2118/21621-PA

3. Andersen MA (1995) Petroleum research in North Sea chalk. RFRogaland Research, Stavanger, Norway

4. D'Heur M (1984) Porosity and hydrocarbon distribution in the North Sea chalk reservoirs. Mar Pet Geol 1:211-238. https://doi. org/10.1016/0264-8172(84)90147-8

5. Jakobsen F, Ineson JR, Kristensen L, Stemmerik L (2004) Characterization and zonation of a marly chalk reservoir: the lower cretaceous Valdemar field of the Danish central graben. Pet Geosci 10:21-33. https://doi.org/10.1144/1354-079303-584

6. Fabricius IL, Røgen B, Gommesen L (2007) How depositional texture and diagenesis control petrophysical and elastic properties of samples from five North Sea chalk fields. Pet Geosci 13:81-95. https://doi.org/10.1144/1354-079306-707

7. Sylte JE, Hallenbeck LD, Thomas LK (1988) Ekofisk formation pilot waterflood. SPE annual technical conference and exhibition. Society of Petroleum Engineers, Houston, Texas, pp 1-16

8. Hallenbeck LD, Sylte JE, Ebbs DJ, Thomas LK (1991) Implementation of the Ekofisk field waterflood. SPE Form Eval 6:284-290. https://doi.org/10.2118/19838-PA

9. Christian TM, Currie JC, Lantz TG, Rismyhr O, Snow SE (1993) Reservoir management at Ekofisk field. SPE annual technical conference and exhibition. Society of Petroleum Engineers, Houston, TX, pp 1-10

10. Graue A, Viksund BG, Baldwin BA (1999) Reproducible wettability alteration of low-permeable outcrop chalk. SPE Reserv Eval Eng 2:134-140. https://doi.org/10.2118/55904-PA

11. Zhang P, Austad T (2005) Waterflooding in chalk: relationship between oil recovery, new wettability index, brine composition and cationic wettability modifier. SPE Europec/EAGE annual conference. Society of Petroleum Engineers, Madrid, Spain, pp $1-7$
12. Maas J, Springer N (2014) Advanced core measurements "best practices" for low reservoir quality chalk. https://www.scawe b.org/technology/best-practicesfor-chalk/

13. Cuiec LE (1991) Evaluation of reservoir wettability and its effects on reservoir recovery. In: Morrow NR (ed) Interfacial phenomena in oil recovery. Marcel Dekker, New York, NY, pp 319-373

14. Donaldson EC, Thomas RD, Lorenz PB (1969) Wettability determination and its effect on recovery efficiency. Soc Pet Eng J 9:13-20. https://doi.org/10.2118/2338-PA

15. Valori A, Nicot B (2018) A review of 60 years of NMR wettability. International symposium of the society of core analysts held in Trondheim. Society of Petrophysicists and Well-Log Analysts, Trondheim, Norway, pp 1-9

16. Grate JW, Dehoff KJ, Warner MG, Pittman JW, Wietsma TW, Zhang C, Oostrom M (2012) Correlation of oil-water and air-water contact angles of diverse silanized surfaces and relationship to fluid interfacial tensions. Langmuir 28(18):7182-7188

17. Wang W, Gupta A (1995) Investigation of the effect of temperature and pressure on wettability using-modified pendant drop method. In: InSPE Annual Technical Conference and Exhibition Jan 1. Society of Petroleum Engineers

18. Xie X, Morrow NR, Buckley JS (2002) Contact angle hysteresis and the stability of wetting changes induced by adsorption from crude oil. J Pet Sci Eng 33(1-3):147-159

19. Rao DN (2022) Measurements of dynamic contact angles in solid-liquid-liquid systems at elevated pressures and temperatures. Colloids Surf A Physicochem Eng Aspects 206(1-3):203-216

20. Røgen B, Fabricius IL (2002) Influence of clay and silica on permeability and capillary entry pressure of chalk reservoirs in the North Sea. Pet Geosci 8:287-293. https://doi.org/10.1144/petge o.8.3.287

21. Hu X, Hu S, Jin F, Huang S (2017) Physics of petroleum reservoirs. Springer, Berlin

22. Strand $\mathrm{S}$, Hjuler $\mathrm{H}$, Torsvik R, Pedersen J, Madland M, Austad T (2007) Wettability of chalk: impact of silica, clay content and mechanical properties. Pet Geosci 13:69-80. https://doi. org/10.1144/1354-079305-696

23. Klewiah I, Piñerez Torrijos ID, Strand S, Puntervold T, Konstantinopoulos M (2019) Adsorption of crude oil polar components onto silica-rich chalk and its impact on wetting. SPE Norway one day seminar. Society of Petroleum Engineers, Bergen, Norway, pp 1-15

24. Fabricius IL (2007) Chalk: composition, diagenesis and physical properties. Bull Geol Soc Den 55:97-128

25. Nourani M, Schovsbo NH, Meyer AG, Sigalas L, Lorentzen HJ, Stemmerik DOL (2018) An index for predicting porosity in chalk by XRF. Poster presented at DHRTC conference. DHRTC, Copenhagen, Denmark, pp 1-2

26. Spiteri E, Juanes R, Blunt M, Orr F (2008) A new model of trapping and relative permeability hysteresis for all wettability characteristics. SPE J 13:277-288. https://doi.org/10.2118/96448-PA

27. Kozeny J (1927) Ueber kapillare leitung des wassers im boden. Sitzungsber Akad Wiss Wien 136:271-306

28. Mortensen J, Engstrom F, Lind I (1998) The relation among porosity, permeability, and specific surface of chalk from the gorm field, Danish North Sea. SPE Reserv Eval Eng 1:245-251. https://doi.org/10.2118/31062-PA

29. Tiab D, Donaldson EC (2015) Petrophysics: theory and practice of measuring reservoir rock and fluid transport properties. Gulf Professional Publishing, Houston, TX

30. Abedini A, Torabi F (2015) Pore size determination using normalized J-function for different hydraulic flow units. Petroleum 1:106-111. https://doi.org/10.1016/j.pet/m.2015.07.004

31. Washburn EW (1921) The dynamics of capillary flow. Phys Rev 17:273-283. https://doi.org/10.1103/PhysRev.17.273 
32. Salathiel RA (1973) Oil recovery by surface film drainage in mixed-wettability rocks. J Pet Technol 25:1216-1224. https:// doi.org/10.2118/4104-PA

33. Borysenko A, Clennell B, Sedev R, Burgar I, Ralston J, Raven $M$, Dewhurst $D$, Liu K (2009) Experimental investigations of the wettability of clays and shales. J Geophys Res Solid Earth 114:B07202. https://doi.org/10.1029/2008JB005928

34. Nourani M, Tichelkamp T, Torsæter O, Øye G (2013) Analytical investigation of the effect of the vertical component of water oil interfacial tension on capillary number. 2nd International conference on engineering geophysics. EAGE, AI Ain, UAE, pp 2214-4609

35. Moore TF, Slobod RL (1956) The effect of viscosity and capillary on the displacement of oil by water. Prod Mon 9:20-22

36. Christensen HF, Springer N, Olsen D, Øyno L, Lind I, Andersen M, Mørch E (1996) Joint chalk research phase IV reservoir management in a compacting enviorment. Final Report

37. Japsen P (1998) Regional velocity-depth anomalies, North Sea chalk: a record of overpressure and Neogene uplift and erosion. AAPG Bull 82:2031-2074

38. Japsen P, Bidstrup T (1999) Quantification of late cenozoic erosion in Denmark based on sonic data and basin modelling. Bull Geol Soc Den 46:79-99

39. Jerauld GR, Rathmell JJ (1997) Wettability and relative permeability of Prudhoe bay: a case study in mixed-wet reservoirs. SPE Reserv Eng 12:58-65. https://doi.org/10.2118/28576-PA
40. Hamon G (2000) Field-wide variations of wettability. SPE annual technical conference and exhibition. Society of Petroleum Engineers, Dallas, TX, pp 1-9

41. Hamon G (2004) Revisiting Ekofisk and Eldfisk wettability. SPE annual technical conference and exhibition. Society of Petroleum Engineers, Houston, TX, pp 1-8

42. Lindgreen $\mathrm{H}$, Fallick $A E$, Jakobsen F, Springer $\mathrm{N}$ (2012) The tight Danian Ekofisk chalk reservoir formation in the south Arne field, North Sea: mineralogy and porosity properties. J Pet Geol 35(3):291-309

43. Puntervold T, Strand S, Austad T (2007) Water flooding of carbonate reservoirs: Effects of a model base and natural crude oil bases on chalk wettability. Energy Fuels 21(3):1606-1616

44. Rao DN (1996) Wettability effects in thermal recovery operations. In: InSPE/DOE Improved Oil Recovery Symposium Jan 1. Society of Petroleum Engineers

45. Anderson WG (1986) Wettability literature survey-part 1: rock/ oil/brine interactions and the effects of core handling on wettability. J Petrol Technol 38(10):1-125

Publisher's Note Springer Nature remains neutral with regard to jurisdictional claims in published maps and institutional affiliations. 